\title{
Use of a Rotational Flap with Soft Tissue Graft and Tunneling Technique for Ovate Pontic Site Development for a Highly Esthetic Outcome: A Case Report
}

\author{
Hafiz A Adawi
}

\begin{abstract}
Aim and objective: The objective of therapy was to replace the missing teeth with a restoration that closely adhered to the natural teeth and soft tissue contour to provide an esthetic outcome.

Case description: A 19-year-old male reported a failed fixed partial denture (FPD) in the maxillary left central incisor. The abutment extended to the maxillary right central incisor and the maxillary left lateral incisor. Radiographic examination revealed that the neighboring maxillary right central incisor abutment was nonrestorable. The treatment plan was the extraction of the maxillary right central incisor with socket preservation, modification of the pontic sites for placement of an ovate pontic for the replacement of the missing maxillary upper central incisors with an FPD with the maxillary lateral incisors serving as the abutment teeth. The pontic sites were corrected with a U-shaped flap extended $5 \mathrm{~mm}$ palatal from the mid-crestal line. The incision was avoided at the interdental papilla area. The facial flap was elevated. The facial soft tissue was vertically tunneled. The flap was flipped into the facial tunnel and stabilized with horizontal nylon matrix sutures. The surgical site was stabilized with a provisional FPD with an ovate pontic. The final restoration was a full zirconia facial veneered FPD.

Results: Surgical site showed significant healing with a natural emergence profile, and interdental papillae filling the gingival embrasure, showing no evidence of recession. At the 1-year follow-up, the gingival thickness improved and the pontic emergence profile was natural. A very stable result for soft tissue volume and interdental papillae were seen.

Conclusion: According to the result obtained with rotational flap, it can be used for small anterior defects with promising results, without the need for bone graft procedures or additional tissue graft.

Clinical significance: With proper case selection, the use of a rotational flap with a tunnel technique and an ovate pontic in the anterior esthetic region is an alternative treatment option that can successfully restore masticatory and esthetic function.

Keywords: Esthetic zone, Ovate pontic, Rotational flap, Tissue graft, Tunnel technique.

The Journal of Contemporary Dental Practice (2021): 10.5005/jp-journals-10024-3203
\end{abstract}

\section{INTRODUCTION}

A pontic refers to the artificial part of a fixed dental prosthesis that mimics the lost tooth's appearance and function. Restoration can prove challenging in the case of missing anterior teeth as the size, shape, shade, and profile of the pontic must emulate natural teeth and support the adjacent papilla. ${ }^{1}$ The ovate pontic, initially described by Abrams, ${ }^{2}$ when used in the esthetic zone may provide an unerring simulation of natural teeth while achieving optimum esthetics with integration. ${ }^{3}$ Bone loss and residual alveolar ridge resorption are inescapable sequelae of teeth extraction. ${ }^{4}$ There are rapid changes in the bone and surrounding tissues followed by a gradual reduction in dimensions. It is estimated that up to $50 \%$ of the alveolar bone loss and $85 \%$ of the ridge resorption takes place in the first 3 months after tooth extraction. ${ }^{4-7}$ Alveolar bone loss of approximately was $3.87 \mathrm{~mm}$ horizontally and $1.67 \mathrm{~mm}$ vertically occurs at the mid-facial area after 6 months postextraction. ${ }^{5}$ Horizontal dimension change is of $32 \%$ is seen at 3 months and $29-63 \%$ at $6-7$ months. The bone loss is proportional to the number of teeth extracted and increases with each tooth extracted..$^{8}$ Extraction of four or more teeth can lead to residual alveolar atrophy. ${ }^{8}$ The socket anatomy and thickness of the buccal bone plate at the site of extraction determine the postextraction bone loss. ${ }^{9}$ Areas with less than $1 \mathrm{~mm}$ buccal bone thickness can experience up to $7.5 \mathrm{~mm}$ of resorption after extraction. Areas with a buccal socket bone
Department of Prosthetic Dental Science, College of Dentistry, Jazan University, Jazan, Saudi Arabia

Corresponding Author: Hafiz A Adawi, Department of Prosthetic Dental Science, College of Dentistry, Jazan University, Jazan, Saudi Arabia, Phone: +966501949962, e-mail: Hafed95@gmail.com

How to cite this article: Adawi HA. Use of a Rotational Flap with Soft Tissue Graft and Tunneling Technique for Ovate Pontic Site Development for a Highly Esthetic Outcome: A Case Report. J Contemp Dent Pract 2021;22(10):1191-1196.

Source of support: Nil

Conflict of interest: None

plate thickness greater than $1 \mathrm{~mm}$ experience a lesser magnitude of bone loss of up to $1.1 \mathrm{~mm} .^{9}$ Augmentations of the residual alveolar ridge with bone grafts or connective tissue grafts show a significant result in maintaining the thickness of the residual ridge and level of gingival tissue. ${ }^{10}$ Excessive horizontal or facial resorption of residual alveolar ridge affects the ability of the dentist to make an ovate-shaped pontic design. ${ }^{10}$ The ovate pontic design improves the esthetic outcome of the dental prosthesis, is highly tolerated by the patient and is easy to clean. ${ }^{10}$ Replace the missing tooth with an ovate pontic immediately after tooth extraction has the advantage of ridge preservation, maintain the residual alveolar ridge contour, and esthetic 
outcome. ${ }^{11}$ Socket preservation at the extraction site with bovine bone and coverage with collagen membrane improve the bone and soft tissue volume and height and interdental papilla after the extraction. ${ }^{11}$ However, the surgical trauma and flap design and elevation affect the thickness of the soft tissue and reduce the potential of soft tissue fill at the interdental papilla area. ${ }^{12}$ It is highly recommended to replace the exacted tooth immediately with an ovate pontic provisional restoration. Cases of extracted and missing teeth without a provisional ovate pontic may require a surgical correction of the residual alveolar ridge before the final prosthesis.

Abrams reported a "roll technique" for soft tissue management that allowed the correction of minor horizontal defects and improved buccal soft tissue profile. ${ }^{2}$ Diverse clinical advancements with technical innovations have led to many modifications of this technique. ${ }^{13-15}$ These techniques have expanded to meet a wide range of indications. Similarly, tunneling techniques initially described for correcting recession defects ${ }^{16,17}$ can now be successfully applied in areas of soft tissue around the esthetic zone in a variety of clinical situations. ${ }^{18-20}$

This case report illustrates the application of rotational flap with vertical tunneling to simplify the augmentation of residual ridge placement of an ovate pontic in the anterior maxillary esthetic region.

\section{Case Description}

A 19-year-old male patient reported to the clinic with a failed fixed partial denture (FPD) (Fig. 1) with a chief complaint of "can I get my missing tooth replaced." The patient reported a history of trauma 4 years ago related to maxillary left central incisor (\#9) when a football accident caused avulsion and loss of that tooth. An FPD was used to replace the missing tooth with an abutment extending to the maxillary right central incisor (\#8) and another abutment to the maxillary left lateral incisor (\#10). The pontic replaced the missing maxillary left central incisor. On radiographic examination, the periapical radiograph and cone-beam computed tomography scan showed the neighboring abutment tooth maxillary right central incisor as nonrestorable (Fig. 1). It was indicated for extraction because of unsuccessful endodontic treatment and now showed evidence of a periapical lesion. The root appeared unusually wide with an open apex, resin cemented threaded post, and the abutment was severely decayed (Fig. 2).

The buccal plate of the maxillary right central incisor was thin and was likely to fracture at the time of extraction (Fig. 2). The residual alveolar ridge of the missing maxillary left central incisor was very thin and showed signs of significant horizontal bone loss (Fig. 2C). The maxillary left lateral incisor (\#10) was overprepared with reduced healthy periodontium. However, the pulp was within the normal limit response for a cold test.

The patient wanted a highly esthetic prosthesis to replace the missing tooth. The objective of restorative therapy was to replace the missing teeth with teeth that had the proper esthetic dimensions and displayed a natural soft tissue contour to achieve an optimum esthetic result. A treatment plan consisting of extraction with socket preservation for maxillary right central incisor (\#8), modification of the pontic sites for placement of an ovate pontic for the replacement of the missing maxillary upper
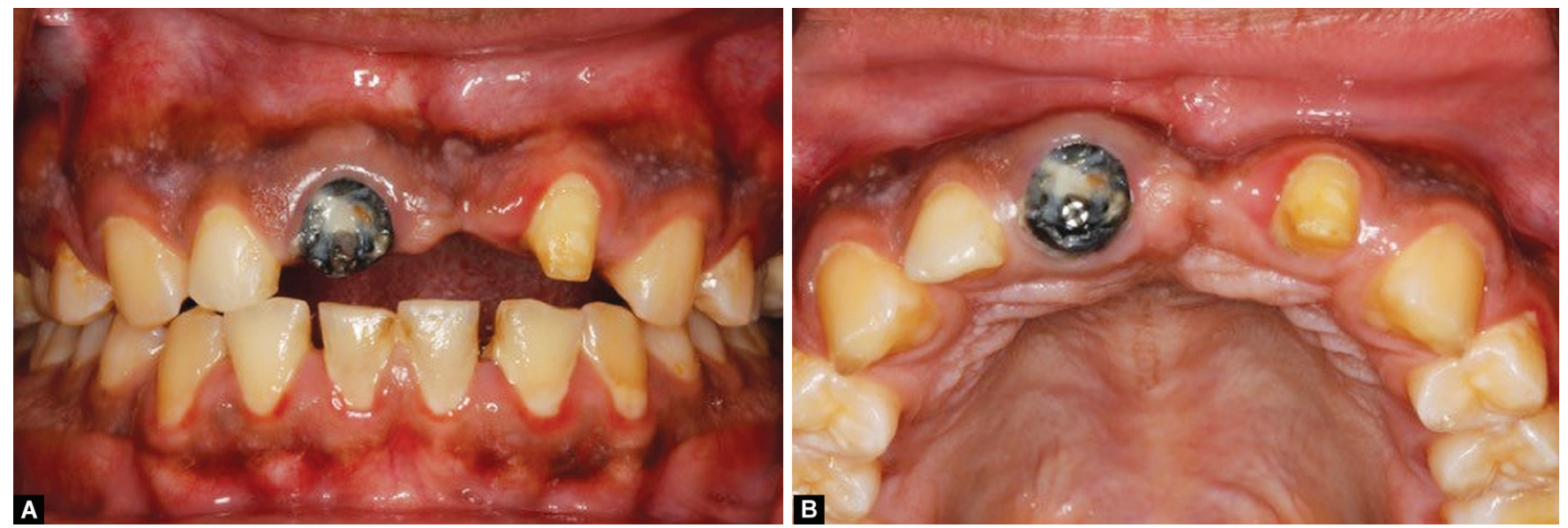

Figs 1 A and B: (A) Patient's initial frontal intraoral photograph; (B) Patient's initial occlusal intraoral photograph
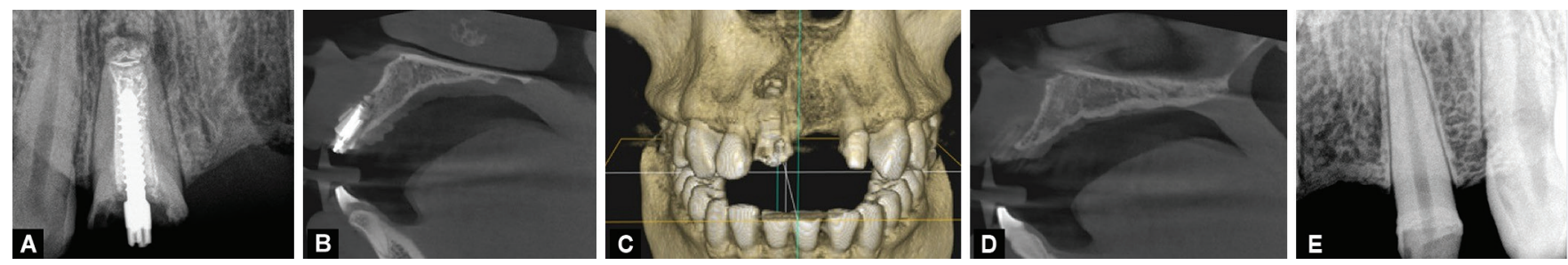

Figs 2A to E: (A) Preoperative periapical radiographic tooth: \#8; (B) Preoperative cone-beam computed tomography (CBCT) radiographic tooth: \#8; (C) Preoperative CBCT radiographic teeth; (D) Preoperative CBCT radiographic tooth: \#9; (E) Preoperative periapical radiographic tooth: \#10 
central incisors with an FPD extending from the maxillary right lateral incisor across the midline to the maxillary left lateral incisor (\#7-\#8-\#9-\#10). The maxillary lateral incisors serve as the abutment teeth.

\section{Treatment Procedure}

Atraumatic extraction of tooth maxillary right central incisor was performed using an Exomed instrument (Item\# 7500 kit, Medesy, Italy) to preserve the buccal plate (Fig. 3). Socket preservation was done and grafted with 0.5 cc of small particle cortical-cancellous allograft 150-1000 $\mu \mathrm{m}$ (Ceno Biologics, UK) and covered with a collagen membrane (Ceno Biologics, UK) sutured using nylon suture 4/0 (Daclon, MIS, Humanus, Sweden) (Fig. 3).

The patient was recalled after 2 weeks for evaluation of soft tissue healing and suture removal. Maxillary right lateral incisor (\#7) was prepared for full crown restoration (Fig. 4). A provisional FPD extending from the maxillary right lateral incisor connecting the maxillary central incisors and the maxillary left incisor (\#7-(8)-(9)-10) was fabricated using an acrylic resin (UNIFASTIII, GC, Tokyo). The pontic site of the maxillary right central incisor (\#8) was modified to convex, ovate, with an additional $1 \mathrm{~mm}$ extension over the soft tissue. The pontic site of the maxillary left central incisor (\#9) was not modified to avoid any further surgical trauma of the healing site.
The provisional acrylic FPD was temporarily cemented (FreeGenol, GC, Tokyo) to abutment teeth, i.e., the maxillary lateral incisors.

After 3 months of healing, the secondary treatment plan involving guided bone regeneration of the area of missing maxillary central incisors followed by implant placement was proposed to the patient. However, the patient declined any additional bone grafting or implant placement.

The abutment teeth show no sign of mobility or primary occlusal trauma. The patient recognized the difference between the pontics on the maxillary central incisors. He stated, "the food can get underneath this area only and is difficult to clean," pointing to the maxillary left central incisor.

\section{Surgical Technique}

The pontic site of the maxillary left central incisor was modified with a U-shaped flap extended $5 \mathrm{~mm}$ palatally (Fig. 5A) from the mid crestal line to avoid crestal incision at the midcrestal line or interdental papilla area (Fig. 4B). This flap modification avoided the midcrestal incision in order to reduce the healing period and accelerate the interdental papilla fill between the pontic. The facial flap was elevated and vertically tunneled (Fig. 5B) then the flap flipped into the facial tunnel (Figs $5 \mathrm{C}$ and $6 \mathrm{~A}$ ) and stabilized with a horizontal 4/0 nylon matrix suture (Fig. 6B). The epithelial layer of
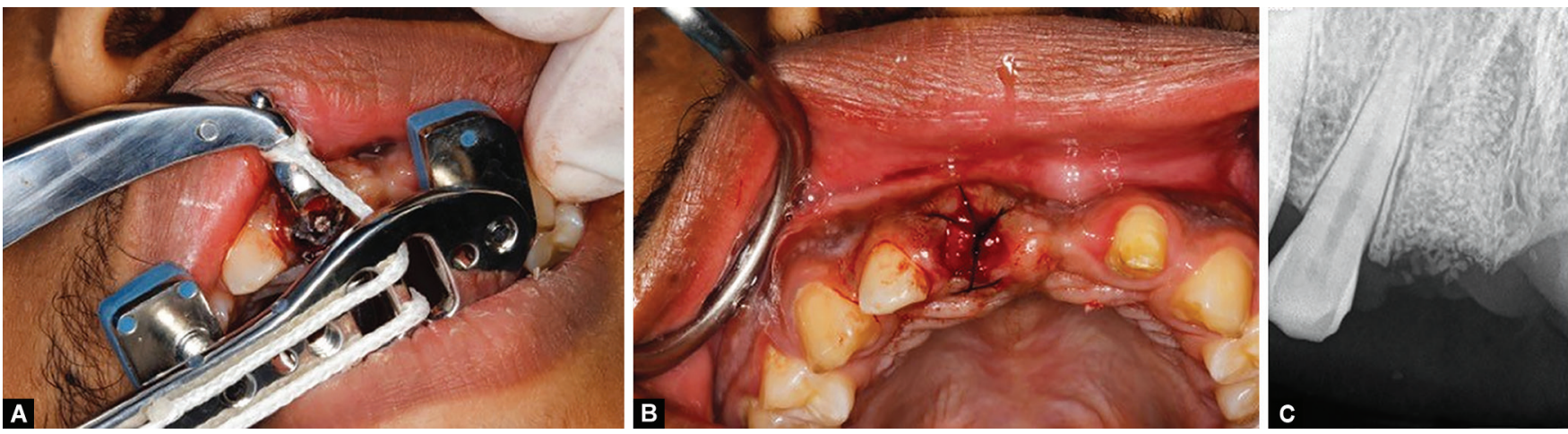

Figs 3A to C: (A) Atraumatic extraction of tooth: \#8 with exomed instrument; (B) Photograph for extracted tooth: \#8; (C) Socket preservation after extraction of tooth: \#8 with bone graft
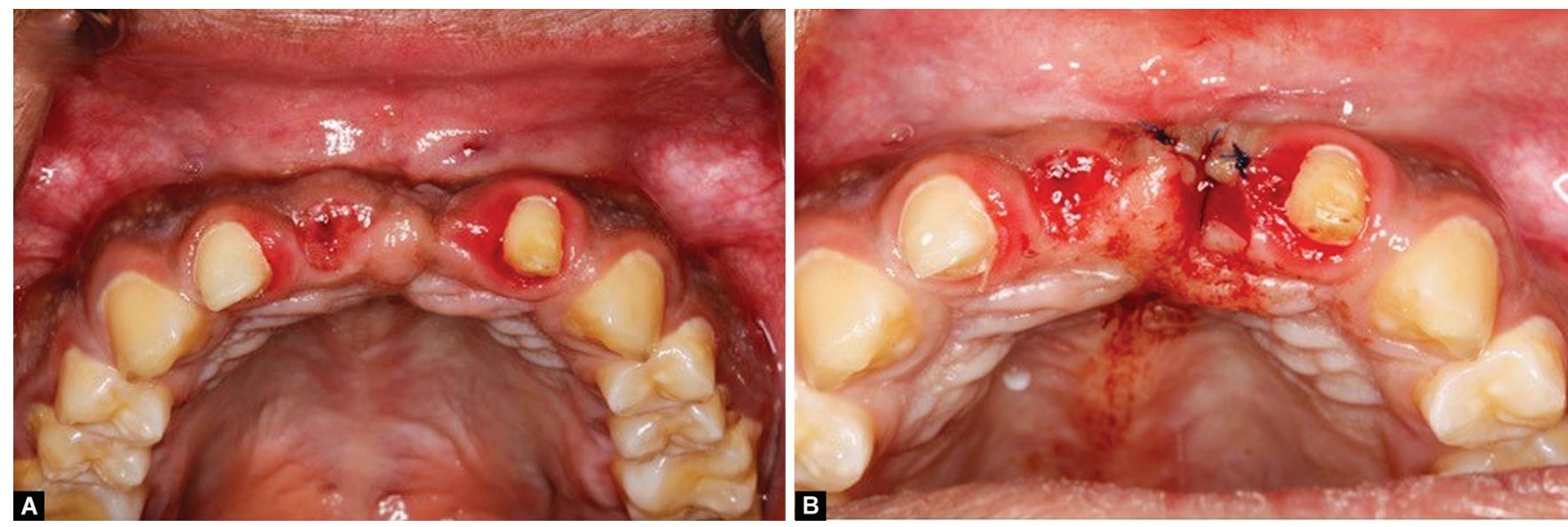

Figs 4A and B: (A) Occlusal photograph of 2 weeks of socket healing; (B) Occlusal photograph of the result after flap elevation and facial soft tissue tunneling and suture 

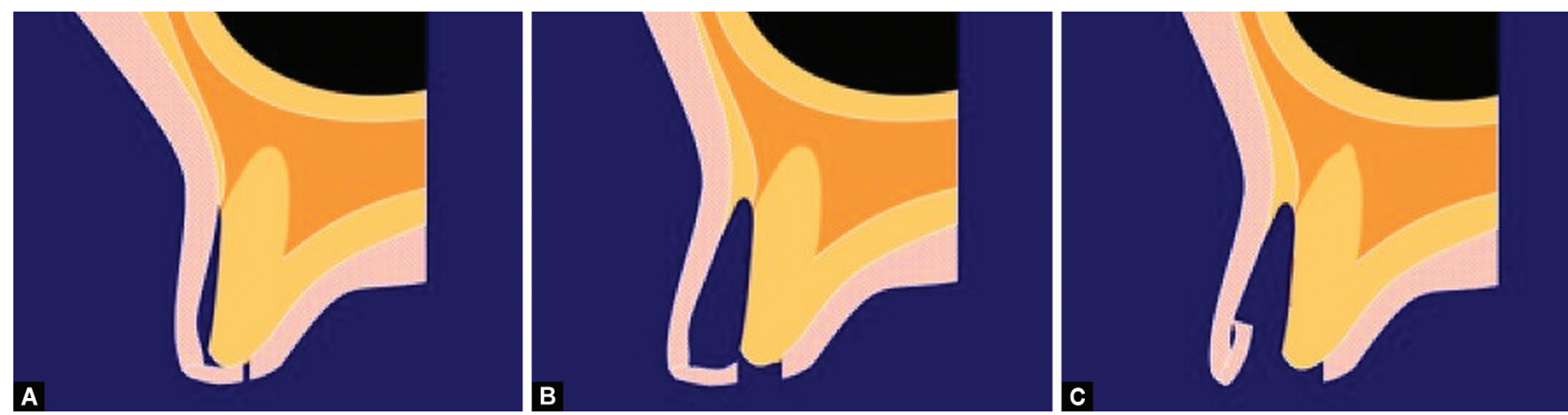

Figs 5A to C: Illustration diagram for: (A) Palatal paracrestal incision; (B) Flap elevation and facial soft tissue tunneling; (C) Rotation of the flap elevation and insertion in the facial tunnel
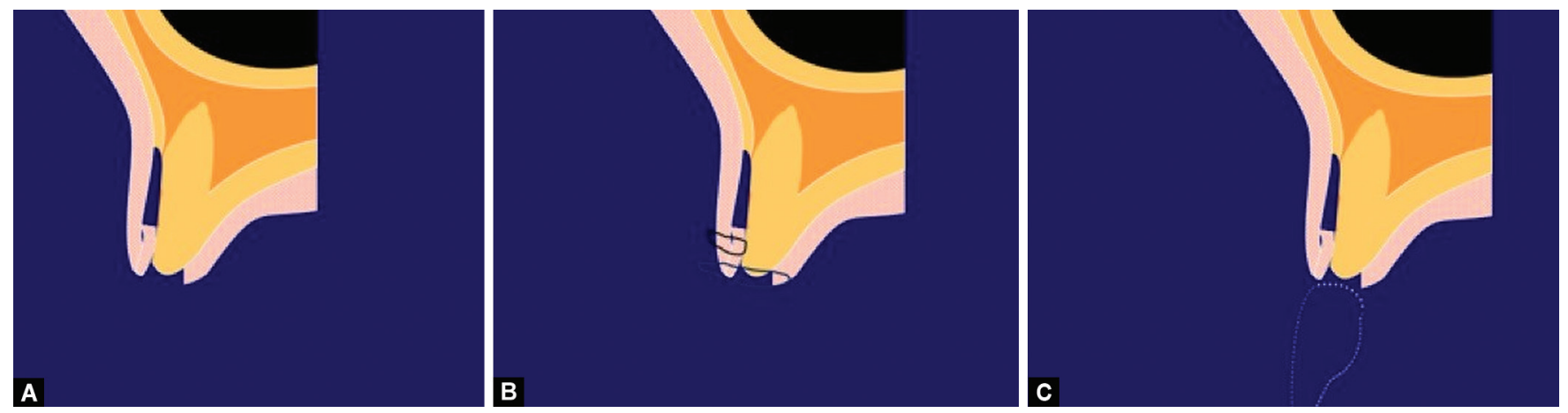

Figs 6 A to C: Illustration diagram for: (A) Soft tissue adaptation; (B) Soft tissue suturing; (C) Pontic support of soft tissue healing

the flap was maintained to increase the thickness of soft tissue and accelerate soft tissue healing. The provisional FPD was modified to ovate pontic extended $2 \mathrm{~mm}$ within the soft tissue (Figs 6C and $7 \mathrm{~A}$ ). The FPD cemented to the abutment teeth and over the surgical site with temporary cement.

The patient returned to the clinic after 3 weeks for a follow-up visit. He reported satisfaction with the treatment outcome (Fig. 7B) and declined further treatment.

The surgical site showed significant healing with thick soft tissue (Fig. 7C) and natural emergence profile, interdental papillae filling the gingival embrasure, and no recession. The temporary bridge was replaced with a permanent all-ceramic Zirconia FPD framework (Ceramill CAD/CAM material, Amann Girrbach GmbH, Germany) with facial veneering with Emax ceramic (EMAX, Ivoclar Vivodent, USA) (Fig. 8).

At the 1-year follow-up visit, the esthetic outcome of the FPD with an ovate pontic was highly appreciated by the patient (Fig. 9).

\section{Discussion}

The smile is the focal point of a person's appearance. Restorations in the anterior hard and soft tissue areas that contribute to a smile have always been challenging for a clinician, especially in cases of high lip lines that reveal the gingiva. Replacing teeth in this esthetic zone is difficult as the restoration has to mimic the natural contours of the teeth and soft tissue, some of which may have undergone resorption. Insufficient bone in this region can further complicate treatment and diminish the final esthetic result. ${ }^{21}$

Four strategies were utilized in this case for an optimum esthetic outcome. First, the extraction procedure was atraumatic following which the socket was preserved to maintain the maximum volume of the residual alveolar ridge after extraction. ${ }^{11}$ Second, the mid-crestal incision was avoided. A palatal paracrestal incision was employed for improving the gingival soft tissue thickness. ${ }^{12}$ The forethought of surgically maintaining the papilla by using a papilla preserving incision of the interdental area avoided papillary recession and black triangles between the pontics and teeth. ${ }^{12}$ Third, the use of the flap tissue to graft and increase the facial contour of the ridge simultaneous with shaping the ridge as a concave surface. Fourth, utilizing the convex pontic surface with 1-2 $\mathrm{mm}$ pressure to support the desired shape of soft tissue. ${ }^{22}$

The rotational flap with the placement of the provisional restoration was ideal for site development and eliminated the need for second donor site surgery. The pontic site is utilized as the donor site simultaneously as the residual alveolar ridge shape is modified to achieve a concave form with an increase in thickness. The use of the rotational flap reduced surgical trauma, maintained an undamaged vascular network thereby improving healing, and giving a more esthetic result. ${ }^{16}$ This also prevented any food debris buildup in the space underneath the pontic. Interruption of the vascular supply and decreased stability of the flap could lead to unesthetic scar formation which we strived to avoid in the esthetic zone. ${ }^{23}$ 

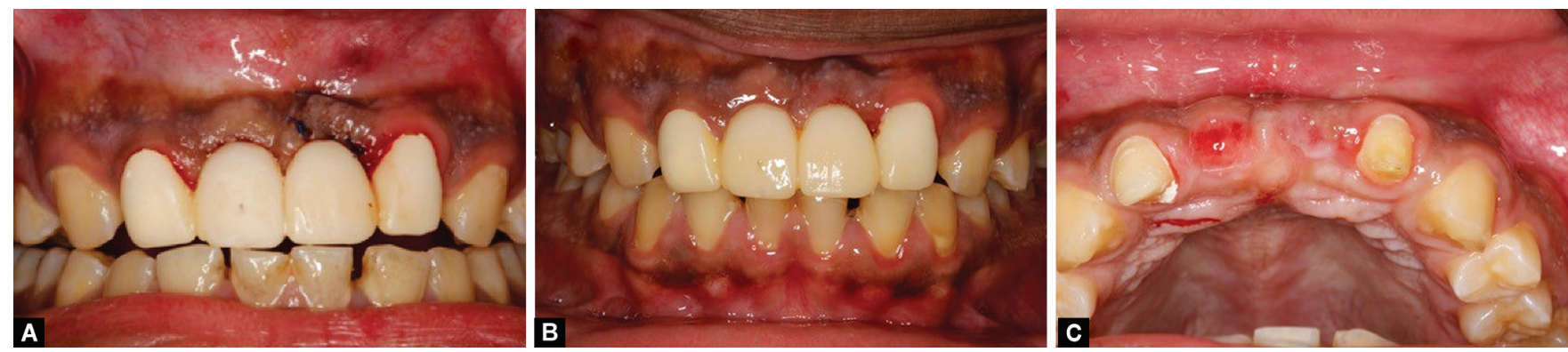

Figs 7A to C: (A and B) Frontal intraoral photographs: (A) Provisional restoration delivered after surgery to support and shape the soft tissue at healing period; (B) Provisional restoration after 3 weeks of healing; (C) Occlusal intraoral photograph of soft tissue after 3 weeks of healing
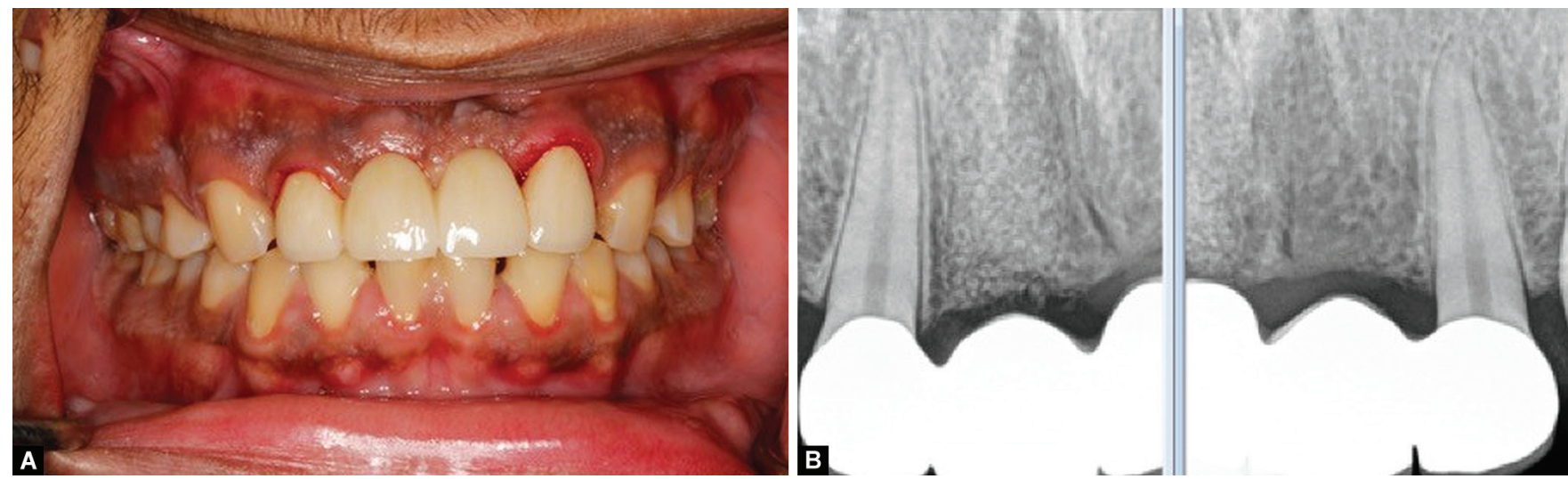

Figs $8 \mathrm{~A}$ and B: (A) Frontal intraoral photograph for the final ceramic FPD restoration; (B) Post cementation periapical radiograph
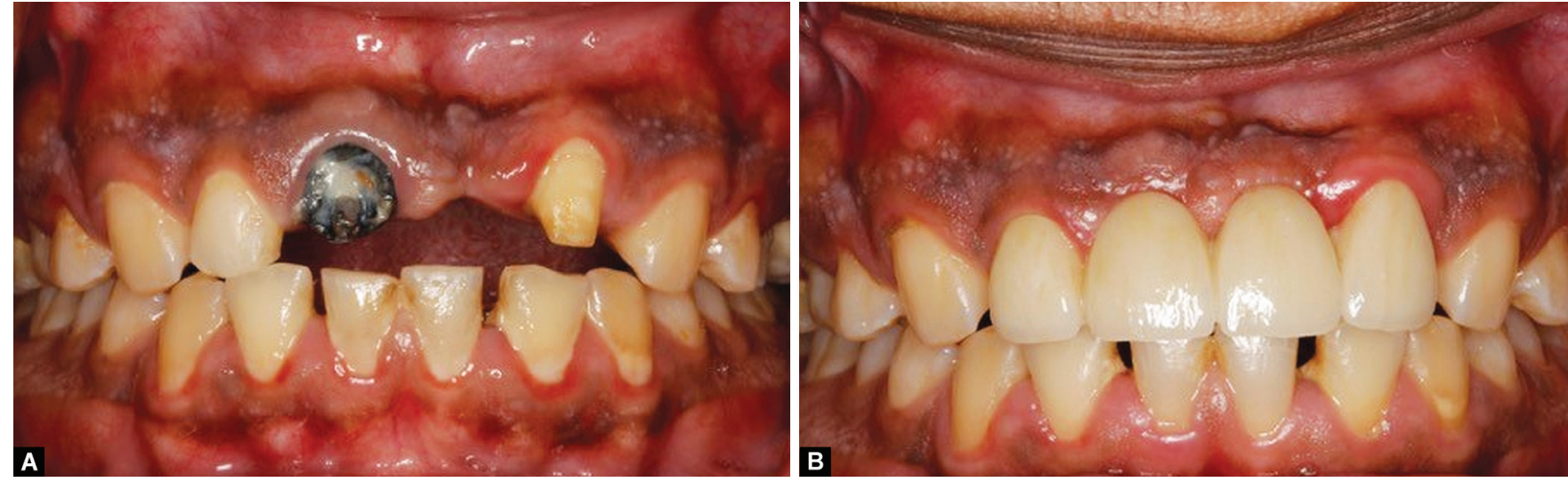

Figs 9A and B: (A) Initial pretreatment frontal photograph; (B) Photograph at 1-year follow-up

A rotational flap can be used for small anterior defects with promising results, without any need for bone graft procedures. Atraumatic management of the tissues and preventing any undue pressure on the wound areas allowed for improved wound healing and leads to a predictable clinical outcome. The use of ovate pontic in the healing period or for final dental prosthesis has the maximum esthetic and patient satisfaction compared to the other pontic designs. ${ }^{4}$ The pontic site with increased gingival width, height, and interdental papillae significantly improved the natural appearance of the restoration. ${ }^{12,22,24}$ Convex, smooth tissue surface of the ovate pontic maintained the health of the soft tissue underneath without any undue pressure on the underlying tissue. ${ }^{22}$ The health of the soft tissue is easily maintained by using dental floss under the convex pontic design. ${ }^{25,26}$ In this case, the ovate pontic was able to mimic the natural emergence profile with adequate tissue contact.

Further treatment was halted at the patient's request. Patients' esthetic perception and treatment needs are too often underestimated or overlooked in the pursuit of "perfection." ${ }^{27}$ The true endpoint of treatment was when the patient reported immense satisfaction with the results.

An overall conservative surgical technique was used in this case which was key to the successful outcome. Tunneling flap procedures reflect a multifunctional approach to soft tissue augmentation in the esthetic zone. In cases involving the esthetic 
zone, treatment planning must be comprehensive considering surgical augmentation and selection of appropriate surgical procedure and graft material keeping the biological, mechanical, and esthetic aspects in mind. Treatment decisions should minimize patient morbidity and consider anatomic factors as well as the patient's esthetic needs.

\section{Conclusion}

The use of a rotational flap with the tunnel technique resulted in a better clinical outcome with excellent final esthetics that was stable through the follow-up period. We find this technique to be an elegant alternative to conventional coronally advanced flap designs. The use of tissue graft appears to be successful and augments the buccal soft tissues and increased marginal soft tissue thickness. Modifying the flap design to a $U$-shape and avoiding the incision at the interdental papilla resulted in an excellent outcome. Ultimately, the success of our treatment was measured in patient satisfaction regarding esthetics and function.

\section{Clinical Significance}

With proper case selection, the use of a rotational flap with a tunnel technique and an ovate pontic in the anterior esthetic region is an alternative treatment option that can successfully restore masticatory and esthetic function.

\section{ACKNOWLEDgments}

Author would like to thank the College of Dentistry, Jazan University, and Saudi Digital Library for their support and providing information on this research.

\section{References}

1. Edelhoff $D$, Spiekermann $H$, Yildirim M. A review of esthetic pontic design options. Quintessence Int 2002;33(10):736-746. PMID: 12553617.

2. Abrams L. Augmentation of the deformed residual edentulous ridge for fixed prosthesis. Compend Contin Educ Gen Dent 1980;1(3): 205-213. PMID: 6950834.

3. Buzayan MM, Mahdey HM, Ning CJ. A new approach for better anterior esthetic using platelet-rich fibrin as sole graft material combined with ovate design dental bridge. J Indian Prosthodont Soc 2020;20(2):219-223. DOI: 10.4103/jips.jips_264_19.

4. Yang Y, Cui FJ, Liu XQ, et al. Effect of provisional restorations with ovate pontics on preservation of the ridge after tooth extraction: case series. Chin J Dent Res 2019;22(3):181-188. DOI: 10.3290/j.cjdr. a43112.

5. Van der Weijden F, Dell'Acqua F, Slot DE. Alveolar bone dimensional changes of post-extraction sockets in humans: a systematic review. J Clin Periodontol 2009;36(12):1048-1058. DOI: 10.1111/j.1600-051X. 2009.01482.x.

6. Tan WL, Wong TLT, Wong MCM, et al. A systematic review of post-extractional alveolar hard and soft tissue dimensional changes in humans. Clin Oral Implants Res 2012;23(Suppl. 5):1-21. DOI: 10.1111/j.1600-0501.2011.02375.x.

7. MacBeth N, Trullenque-Eriksson A, Donos N, et al. Hard and soft tissue changes following alveolar ridge preservation: a systematic review. Clin Oral Implants Res 2017;28(8):982-1004. DOI: 10.1111/clr.12911.

8. Hansson S, Halldin A. Alveolar ridge resorption after tooth extraction: a consequence of a fundamental principle of bone physiology. J Dent Biomech 2012;3:1758736012456543. DOI: 10.1177/1758736012456543.
9. Chappuis V, Engel O, Reyes M, et al. Ridge alterations post-extraction in the esthetic zone: a 3D analysis with CBCT. J Dent Res 2013; 92(12 Suppl.):195S-201S. DOI: 10.1177/0022034513506713.

10. Babiuc I, Geantă I, Tănase G, et al. Clinical aspects dimensional changes of the alveolar crest following tooth extraction-a cone-beam computed tomography study. Acta Medica Transilvanica 2019;24(19):107-110.

11. Khouly I, Strauss FJ, Jung RE, et al. Effect of alveolar ridge preservation on clinical attachment level at adjacent teeth: a randomized clinical trial. Clin Implant Dent Relat Res 2021;23(5):716-725. DOI: 10.1111/ cid.13040. PMID: 34448354

12. Turkyilmaz I, Suarez JC. An alternative method for flapless implant placement and an immediate provisional crown: a case report. J Contemp Dent Pract 2009;10(3):89-95. PMID: 19430631.

13. Barakat K, Ali A, Abdel Meguid A, et al. Modified roll flap a handy technique to augment the peri-implant soft tissue in the esthetic zone: a randomized controlled clinical trial. Tanta Dent J 2013;10(3):123-128. DOI: 10.1016/j.tdj.2013.11.004.

14. Giordano F, Langone G, Di Paola D, et al. Roll technique modification: papilla preservation. Implant Dent 2011;20(3):e48-e52. DOI: 10.1097/ ID.0b013e3182181771.

15. Park S-H, Wang H-L. Pouch roll technique for implant soft tissue augmentation: a variation of the modified roll technique. Int J Periodontics Restorative Dent 2012;32(3):e116-e121. PMID: 22408781

16. Zuhr O, Fickl S, Wachtel $\mathrm{H}$, et al. Covering of gingival recessions with a modified microsurgical tunnel technique: case report. Int J Periodontics Restorative Dent. 2007;27(5):457-463. PMID: 17990442.

17. Zabalegui I, Sicilia A, Cambra J, et al. Treatment of multiple adjacent gingival recessions with the tunnel subepithelial connective tissue graft: a clinical report. Int J Periodontics Restorative Dent 1999;19(2):199-206. PMID: 10635186.

18. Shenoy S, Bhat V, Kottakkunnummal P, et al. Interproximal papilla volumization using vestibular incision subperiosteal tunneling access technique in esthetic rehabilitation. Contemp Clin Dent 2020;11(1):76-78. DOI: 10.4103/ccd.ccd_33_20.

19. Irinakis T, Aldahlawi $S$. The dome technique: a new surgical technique to enhance soft-tissue margins and emergence profiles around implants placed in the esthetic zone. Clin Cosmet Investig Dent 2018;10:1-7. DOI: 10.2147/CCIDE.S154152.

20. Quispe-López N, García-Faria C, Mena-álvarez J, et al. Clinical outcome of a new surgical technique for the treatment of peri-implant dehiscence in the esthetic area. A case report. Appl Sci. 2021;11(11):4781. DOI: 10.3390/app11114781.

21. Bidra AS, Chapokas AR. Treatment planning challenges in the maxillary anterior region consequent to severe loss of buccal bone. J Esthet Restor Dent 2011;23(6):354-360. DOI: 10.1111/ j.1708-8240.2011.00475.x.

22. Tripodakis AP, Constandtinides A. Tissue response under hyperpressure from Convex pontics. Int J Periodontics Restorative Dent 1990;10(5):408-414. PMID: 2098362.

23. Burkhardt $R$, Lang NP. Fundamental principles in periodontal plastic surgery and mucosal augmentation - a narrative review. J Clin Periodontol 2014;41(Suppl. 15):S98-S107. DOI: 10.1111/jcpe.12193.

24. Salama H, Salama MA, Garber D, et al. The interproximal height of bone: a guidepost to predictable esthetic strategies and soft tissue contours in anterior tooth replacement. Pract Periodont Aesthet Dent 1998;10(9):1131-1141; quiz 1142. PMID: 10093558.

25. Zitzmann NU, Marinello CP, Berglundh T. The ovate pontic design: a histologic observation in humans. J Prosthet Dent 2002;88(4): 375-380. DOI: $10.1067 / \mathrm{mpr} .2002 .128758$.

26. Bhuskute M. Ovate pontics: phoenixing the gingival contour. J Int Clin Dent Res Organ 2017;9(2):82-85. DOI: 10.4103/jicdro.jicdro_26_17.

27. Kim SM, Choi YH, Kim YG, et al. Analysis of the esthetic outcome after root coverage procedures using a comprehensive approach. J Esthet Restor Dent 2014;26(2):107-118. DOI: 10.1111/jerd.12085. 